\title{
Brief Analysis on Violence against Children and Adolescents
}

\author{
Pericles Arruda D* \\ Pontifical Catholic University of Sao Paulo, Brazil
}

*Corresponding author: Pericles Arruda D, Pontifical Catholic University of São

Paulo, Brazil, Email: periclesdaniel@yahoo.com.br

\section{Editorial}

Volume 1 Issue 1

Received Date: September 18, 2018

Published Date: September 27, 2018

DOI: $10.23880 /$ jqhe- 16000102

\section{Editorial}

According to the 2017 report of the United Nations Children's Fund (UNICEF) [1] entitled "A familiar face: violence in the lives of children and adolescents", every seven minutes, in some place in the world, a child or adolescent between ages 10 and 19 dies due to some act of violence. The study points out that the most vulnerable group is between 15 and 19, with three time more chances of dying violently, compared to the condition of children and adolescent between ages 10 and 14 .

In 2015, violence was the cause of more than 82 thousand deaths of children and adolescents in the same 10 to 19 age group, of which 24.5 thousand were in Latin America and the Caribbean. The countries presenting the highest death rates coming from conflicts and collective violence of boys are: Syria (327.4 per 100 thousand from the same age group), Iraq (122.6), Afghanistan (49.4), Southern Sudan (29) and Central Africa (18.9). On the other hand, girls: (Syria (224.1), Iraq (84), Afghanistan (34.2), Southern Sudan (15.9) and Somalia (10.1). In all countries, there was incidence of deaths of boys.

The homicide rate of non-Hispanic black boys in the United States from 10 to 19 years old is 30 per 100 thousand, and of white non-Hispanic boys, 1.6. This is a difference of approximately 19 times. In the case of girls, the difference between black non-Hispanics (who are more susceptible to violence) and whites is five times. If the homicide rate of non-Hispanic black boys were used all over the country, the US would be among the ten most deadly countries.

In 2015, Latin American countries with the highest adolescent homicide rates in the 10 to 19 year-old age group for every 100 thousand, were as follows: Venezuela (96.7), Colombia (70.7), El Salvador (65.5), Honduras
(64.9) and Brazil (59). Furthermore, according to data released by UNICEF on this same age group, the average in Latin America and Caribbean is 22.1 homicides per 100 thousand - a rate four times higher than the worldwide average. The region showing the lowest rate is Western Europe, with 0.4 .

In regard to children globally, three quarters (300 million) between ages 2 and 4 suffer psychological violence and/or physical punishment practiced by their caretakers. Approximately 15 million female adolescents between ages 15 and 19 suffer sexual violence during their lives, with nine million of these girls being victimized in 2016 . Only $1 \%$ of those who suffered sought out professional help.

In 38 countries with low and average income, around 17 million adult women declared having being physically forced to have sex in their childhood, while in 28 European countries, approximately 2.5 million young people declared having suffered some type of sexual violence before age 15 .

Generally speaking, these data denounce a dramatic and worrisome situation experienced by many children and adolescents in several of the world's regions and, because of this, their reality cannot be ignored [2]. The data most certainly signal the need for immediate, effective, widespread and thorough combat against violence, involving the participation of society and of public authorities based on an articulated set of actions in several areas, such as health, education, social welfare and public safety.

The occurrences registered serve as basis for reflection on how these acts of violence negatively and directly 


\section{Journal of Quality in Health Care \& Economics}

interfere in the specific development of these victims, as they are types of human rights violations, with thousands of lives mortally affected and stained by the experience of violence.

It is perceived that violence in many regions is already considered a way of life, permitted by the culture and symbolically promoted in social relations permeated by hate, fear, and physical, psychological, moral and social illnesses. By this logic, in thesis, the victims with the least capability of defending themselves - the case of children and adolescents - are the most vulnerable to some type of violence.

Nevertheless, it is important to understand the language of violence appears as a symptom of other situations that are hidden from daily life's view, being that their practice involves several dimensions of a political, economic, cultural and subjective order, because their reasons are multiple and their causes, diverse.
Therefore, actions directed at preventing violence are of great importance: promoting educational action for healthy living; when assisting children and adolescents who have suffered acts of violence, a family-oriented approach should also be considered; and the work of holding those responsible for the violence and their education, which is, in truth, against all of humanity.

\section{References}

1. United Nations Children's Fund (UNICEF) (2017) A familiar face: violence in the lives of children and adolescents. Division of Data, Research and Policy. Nova York/USA.

2. Baptista MV, Voli C (2005) Aproximações ao conceito de negligência. Approaches to the Concept of Negligence Serviço Social \& Sociedade, São Paulo/Brasil, n. 83: 147-156. 